\title{
A Smart Parking Solution for Jeddah City
}

\author{
Ahlam AlHarbi Bashayer AlOtaibi Maram Baatya Zubaida Jastania Maram Meccawy, \\ $\mathrm{PhD}$ \\ Department of Information Systems \\ Faculty of Computing and Information Technology, King Abdulaziz University \\ Jeddah, Kingdom of Saudi Arabia
}

\begin{abstract}
One of the first steps that gets implemented to upgrade the traditional cities to become smart cities is the smart parking. This paper will discuss in detail the Smart Parking System in Jeddah city as one of the solutions that can solve the parking problems. It also will present how the system works, the benefits of the system, some issues that can impact the efficiency of the system and the future improvements.
\end{abstract}

\section{General Terms}

Information systems, urban initiatives

\section{Keywords}

Smart city, transportation, smart parking system, Jeddah city, internet of things application, smartphone application, parking technology

\section{INTRODUCTION}

These days, urban demographics and population growth require new approaches and models to provide public services and new lifestyles. There is a worldwide trend to provide these ideas as improved services with technology which called (Smart). However, policies in urban cities around the world are competing for effective initiatives to apply the concepts of smart cities to ensure modern living standards and to keep pace with the rapid and continuous development of technologies. In fact, some may see the concept of smart cities as a luxury but it will be necessary to improve the quality of life for citizens and increase economic growth in the future. In Saudi Arabia especially in Jeddah city, initiatives are underway to adopt smart cities concepts on several areas such as health, government, energy, transportation, etc. The focus in this paper is in transportation area. This paper introduces the smart parking system as a solution to organize parking process in public spots such as hospitals and markets.

This paper presents transportation and smart parking system in Jeddah as: Section 2 provides an overview of smart city concept in the worldwide. Section 3 presents transportations in Jeddah as an overview of current situation and government's initiatives with parking problems. Section 4 presents smart parking system as a proposed solution with its benefits and issues and in-depth explanation of smart parking application. Finally, Section 5 discusses the system future improvments and conclusion.

\section{SMART CITY CONCEPT}

Smart city is considered to a wide spreading expression that takes more than a certain meaning which after these recent innovative technologies administered within completely different urban contexts. It is also considered to be an over and miss-used expression; it implies an extreme developed revolution in modern current cities.
Cities have been incorporated with modern technology over many years. Although, solving most of the metropolitan challenges is considered by rapid developing digital technologies that have the potential to these challenges. As a result, urban regions turn into -smart cities- [1].

A smart city: is a term appeared at the end of 20th century. Smart cities are claimed to be a well-developed vision to operate city assists by using modern technology applications so it is usually looking forward efficient resources by providing high level of life standards. In smart cities, an innovative infrastructure associated with social and technological applications can be available. In smart cities, new energy will be easy to maintain also provide a suitable environment to solve transportation problems and make it easier. Smartness in cities became one of new forms of governmental and public cooperation. It can be considered that smartness in these cities is an entire system that helps these cities to reach their optimal goal of becoming premium and leaders in all fields [2].

This paper investigates applying preliminary smart city concept in Jeddah, especially in transportation aspect as a first step. Saudi government is developing transportation in Jeddah year by year. But as anywhere, there are still need to more improvements to correspond these demands.

\section{TRANSPORTATION IN JEDDAH 3.1 An Overview of City's Current Transportation System}

Saudi Arabia has a large network of modern roads that varies from highway, two-way and one-way. It links all parts of the country. Most of the main cities have a network of highways, main streets and bystreets.

One of the main projects of Jeddah municipality is transportation and communication, it aims to develop its infrastructure and building a local transportation network within a master plan that contains public transport, studies of traffic density, development of a model to simulate the movement of transport and traffic for the entire Jeddah and development petroleum-based transportations to other energy resources.

Other facilities of the transportation projects are:

\subsubsection{Public Transportation}

That's in under implementation and it will implement by Metro Jeddah Company. The project contains the initial design for metro network, bus network, Corniche tram and sea transportation network.

\subsubsection{Lighting}

To keep pace with the technological developments in the lighting project, A light-emitting diode (LED) used to saving 
the consumed electricity and the control system for the main streets.

\subsubsection{Car's Automatic Parking}

It is a public parking with fees and is in the heart of the historical area. The parking will accommodate more than 1,222 parking spaces and will provides an integrated customer service center. Moreover, the parking includes the provision of many advanced systems.

This paper will focus on parking as it is an important facility in the public roads, malls, university and buildings [3].

\subsection{Parking Problems in Jeddah City}

Parking spots assumed to be a crucial part of any transportation framework. Regarding to the latest research results which states that " 30 percent of urban traffic is caused by drivers and drivers searching for parking spaces" [4]. Hence, parking in nowadays in Jeddah is considered a wasteful process in time and efforts particularly in city center or crowded areas.

Illegal parking behavior is also another problem that can impact on supportability of city transportation framework. Thus, the factors that expand parking problems are highlighted as [5]: lack in local rules and laws which not compatible with the fast growth of economy and bad habits and inconvenient social behavior.

Uncontrolled parking has turned into a difficult issue in Jeddah city, bringing about undesirable traffic problems, air pollution, noise contaminations and lessening simplicity of traveling in or around the town. In addition, increased number of citizens and the quick development of vehicle possession in Saudi Arabia particularly in Jeddah means more demands on habitation, services and parking spots, fundamentally rate the issue. Generally, parking problems happens due to either the indiscreet behavior of car drivers or because of the weak regulations of imposing a punishment [5].

Smart cities initiatives in worldwide are facing common difficulties which in turn could be applying to Jeddah, as such: how government will attract key IT corporates and residential stakeholders to build solutions and set standardizations, identify funding sources at this recession economy and establish and prioritize timelines for these issues [6].

It is significant for Jeddah city to establish new policies and advanced solutions to minimize the negative results of uncivilized practice and to accomplish supportability transportation system [5]. There should be a common nontechnic language between audience and decision-makers to fill the gap and explain the benefits of such changes; generating new economic opportunities, improving the delivery and quality of lives and many others [6].

\section{A SMART PARKING FOR JEDDAH}

It is important for Jeddah as an urban city, to adapt and apply smart parking technology to minimize parking problems. Thus, it is considered as first step that upgrade transportation to become smarter.

\subsection{The Smart Parking System}

Smart parking system is a way to organize parking in the urban cities where drivers can check on their mobile devices for an available real-time parking space before arriving as well as book this available space. The system informs the user about the park space availability through car detection technologies and direct the driver to the destination by using smart navigation mobile map applications. It can be used to organize the parking process effectively in different parking space such as shopping centers, hospitals, hotels, universities and educational institutes, etc. [7]. Indeed, some large cities in Europe, United States and Japan were adopted smart parking system.

Infrastructure for smart transportations and parking will pave the way for other smart cities areas such as; data collections and smart systems. Smart car parking systems have some critical benefits for Jeddah as follows [8], [9], [10]:

- $\quad$ Provide guidance services to citizens and city visitors towards available parking spots in a perfect timing period.

- $\quad$ Provide better civilized environment by minimizing $\mathrm{CO} 2$ gas emission of car pollutants.

- Help to provide acceptable revenues from professional perfect timing control and managing of available parking areas.

- Minimize traffic problems especially in city center, universities, hospitals and entertaining places and Jeddah Cornish.

- Improve drivers' culture about parking rules.

- Decrease traffic management costs.

- Increase streets safety procedure and problem monitoring.

Some issues that may affect the system or some of its features as described in [11]. These include: the battery life of the occupancy sensors, weather conditions may affect the occupancy sensors and the rising costs when installing many gateway devices in each floor of the parking. In addition, slow network connection caused from network bandwidth issues and inefficient infrastructure of some areas in Jeddah.

In this project, to apply the proposed parking system, an area that have a good and high-speed internet network is needed, North of Jeddah is covered with fiber optic network-as shown in [12], which is important for such smart system to work with high efficiency. On the other hand, the proposed system is based on primarily local server because its applied to serve a specific area. In addition, the cloud can be used in parallel with the local server and activated in emergency conditions like problems in operating the local servers.

\subsection{The Smart Parking System}

\subsubsection{System Architecture}

In this section, the architecture of proposed smart parking system is presented in Fig. 1. Also, Table 1 discusses the components of system architecture. An overview of smart parking system components is listed as: 


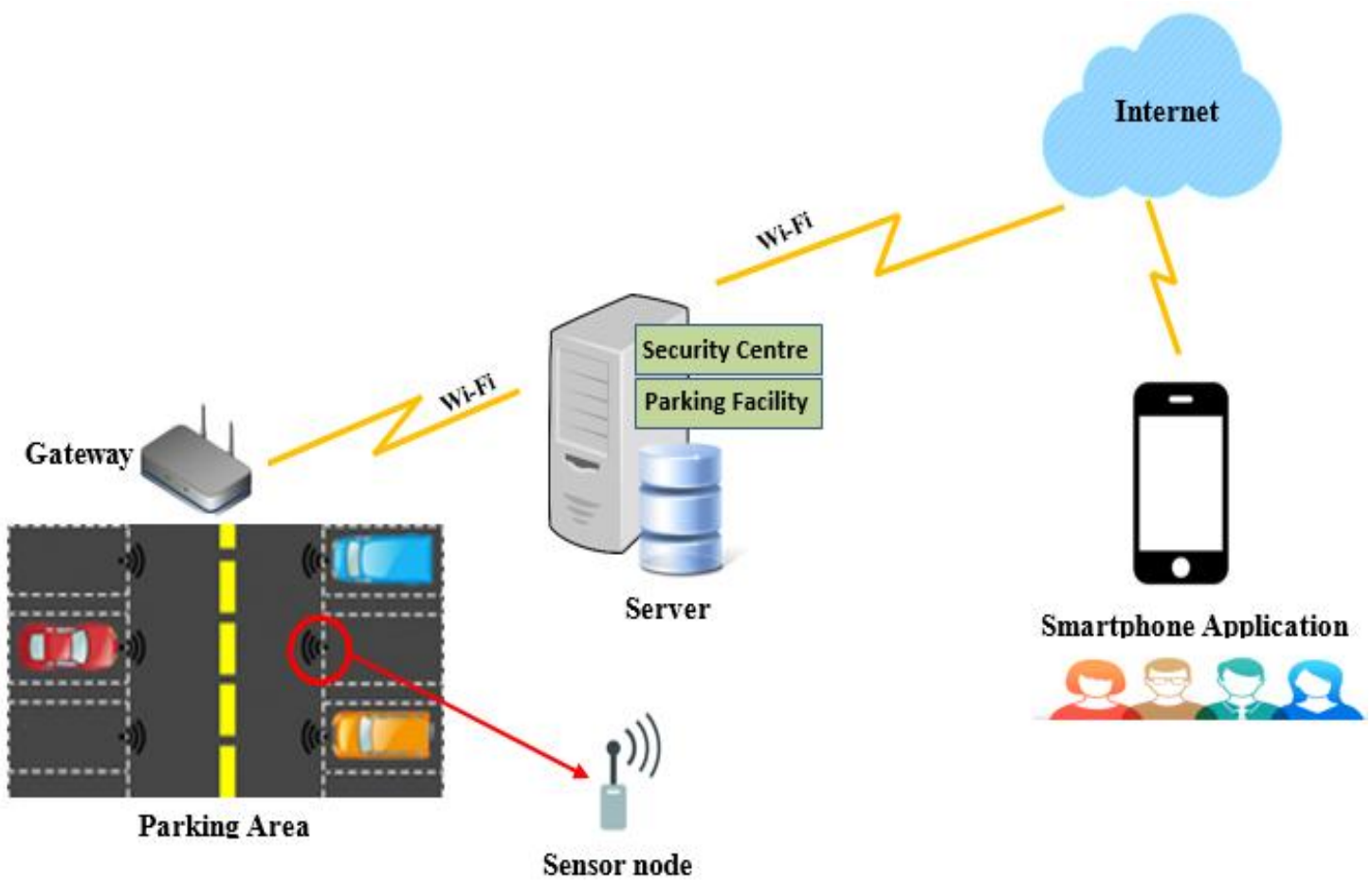

Fig 1: Smart Parking Architecture

Table 1. Smart Parking Components

\begin{tabular}{|c|l|l|l|}
\hline No. & \multicolumn{1}{|c|}{ Component } & \multicolumn{1}{|c|}{ Type } & \multicolumn{1}{c|}{ Role Description } \\
\hline 1 & $\begin{array}{l}\text { (Machine to Machine) } \\
\text { Platform or Server }\end{array}$ & System & $\begin{array}{l}\text { Monitor the whole system and display all information about the } \\
\text { project. } \\
\text { Monitor and process all actions related to the system. } \\
\text { Detect any problems and solve. } \\
\text { Share data with online application. }\end{array}$ \\
\hline 2 & $\begin{array}{l}\text { Application: } \\
\text { Android \& IOS }\end{array}$ & Application & $\begin{array}{l}\text { It can be run on different mobile platforms with a proper GUI for the } \\
\text { users, it is used to guide the user to select and navigate the available } \\
\text { parking spot with a navigation tool as well as with the relevant } \\
\text { notifications. }\end{array}$ \\
\hline 3 & $\begin{array}{l}\text { PIC controller } \\
\text { Gateway) }\end{array}$ & Device & $\begin{array}{l}\text { This gateway device collects the status from the sensors through the } \\
\text { internet and forward it to the server (i.e. receives or transmits data to } \\
\text { all components in the parking location). }\end{array}$ \\
\hline 5 & $\begin{array}{l}\text { IR Sensor } \\
\text { Street Provider }\end{array}$ & Device & $\begin{array}{l}\text { It is a device used to transmit a signal when the car enters the parking } \\
\text { spot or comes out to identify the free parking spaces. }\end{array}$ \\
\hline Security Center & System & $\begin{array}{l}\text { This system provided by the owner of the parking facility (e.g. King } \\
\text { Abdullah Hospital) or the company that manage the location of } \\
\text { parking area including street parking areas. }\end{array}$ \\
\hline
\end{tabular}

\subsubsection{System Operation Mechanism}

The smart parking process will use the components mentioned in Table 1 to perform a sequence of related processes as follows [13], [14]:

\subsubsection{1 (Find and Reserve Spot) Operation:}

1) The user (driver) opens his smartphone application (Android or IOS) and search for the closest parking spot available to his destination through the Find Spot page. 
2) The smartphone application sends the request for information to the parking service provider's system (parking facility or street parking) to get the information about the available parking spots.

3) The parking service provider's system send all data of available parking spots to the mobile application, then the data shows some options of the available spots to the user to select one.

4) After the user selects his desired spot, he proceeds to the reservation step of the parking space, through a confirming message appear to ensure the spot reservation.

5) The parking provider system receives the request to start reservation to the selected spot so it performs checking for the parking spot availability, if it is not available then an alert message will appear by (This parking spot reserved, try again).

\subsubsection{2 (Reserve Timer) Operation:}

6) After the parking spot reservation process done, the duration page appears to the user.

7) The user specifies the duration time to park by entering the approximate time to leave the parking spot.

8) The application will compute the time from the beginning of reservation time to the entered leave time.

9) The decreasing timer will appear in the duration page.

10) After the time out, an alert sound with message notification will appear to the user.

11) As soon as the vehicle is crossing the sensor going out of the parking spot and the timer turned off in case of it still working.
12) The server receives display data finally and updates for new available spot information.

13) In case of laws violations, the service provider's system sends a request for the security system to ask for security help to avoid parking problems with users.

\subsubsection{3 (Spot Location Guide) Operation:}

14) After confirming spot availability and reservation processes, the navigation tool on the smartphone application will guide the user directly to the parking spot location.

15) Delivering the order confirmation for service provider' system and it makes this spot unavailable for a specific time (10 minutes) if the user did not occupy it will become available again for other users.

16) After booking the parking spot in the parking facility or area selected then the state of the led will be as follows: red light will be on (refers to occupied) and the green light will be off (refers to unoccupied).

\subsubsection{System Application Interface}

The proposed system has been initially implemented in Android Studio and developed with two programming languages under Android Studio: Java and XML. Android Studio library also supports GPS and mapping capabilities such as Google Maps API that have been used in this prototype to demonstrate the architecture and to serve as a proof of concepts. The application has been designed to be usable and accessible to the public and it supports both English and Arabic languages. Fig. 2 shows some of the Application interfaces. 


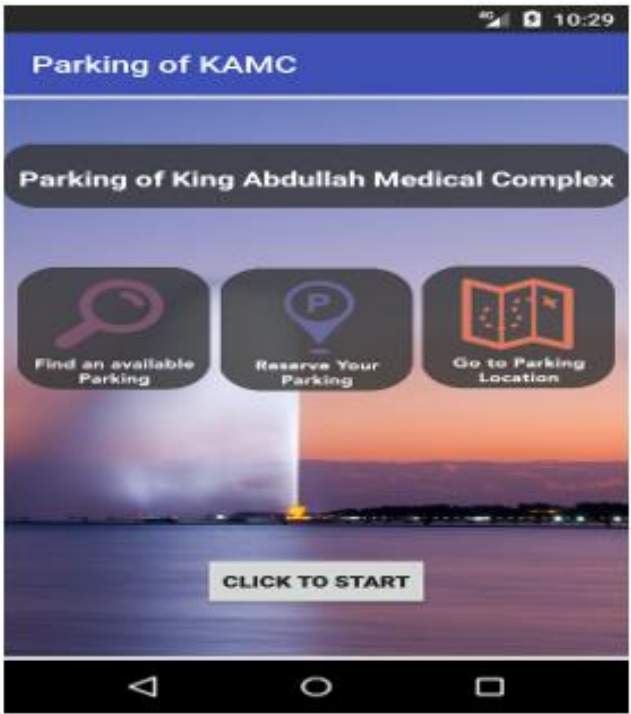

i. Main Application Interface.

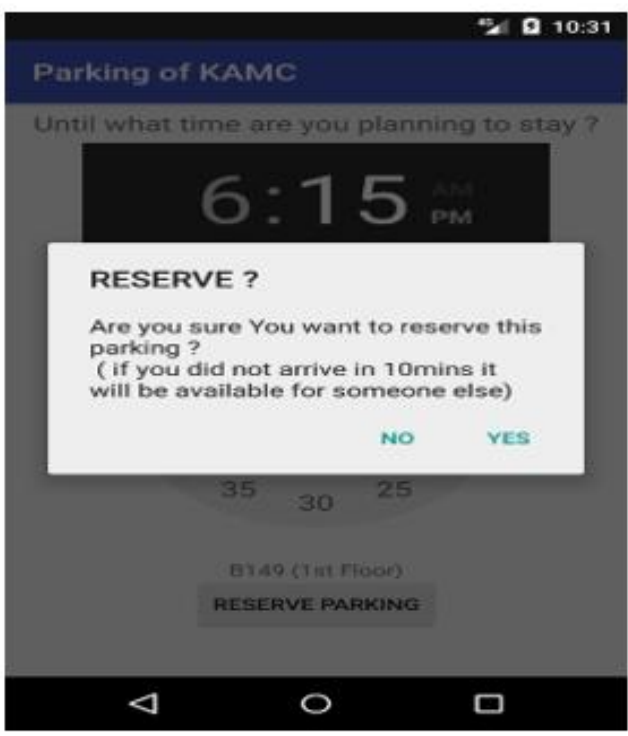

iii. Reserve confirmation.

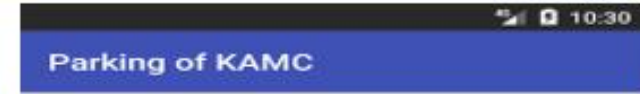

Choose Your Parking from the List

(only available Parkings are shown)

$$
\begin{aligned}
& \frac{\text { Bit49 (1st Floor) }}{\text { G120 (1st Floor) }} \\
& \text { D: } \\
& \text { your Selected Parking is } \\
& \text { 6120 (1st Floor) } \\
& \text { CHoose }
\end{aligned}
$$

$\triangleleft \quad \square$

ii. Select Available Parking Spots Interface.

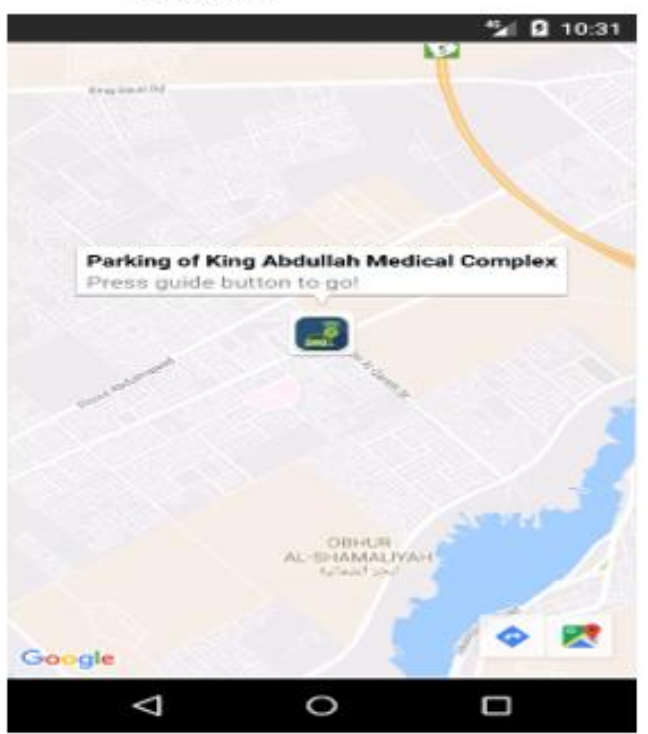

iv. Guide the user Interface.

Fig 2: Smart Parking Application Interfaces

\section{CONCLUSION AND FUTURE WORK}

Saudi Arabia is now seeking to implement (Smart city) concepts across the country. This idea is coming as apart of "Saudi Arabia's Vision 2030". The country hopes at this initiative to decrease negative environmental impacts, attracting internal and external investments and creating jobs. One of the smart city initiatives that will be implemented is (smart parking). First, this paper introduced smart city concept in general. Then it provided the current situation of transportation in Jeddah. It also presented the main problems that affect governments' future improvements at transportation and impede their efforts. The proposed solution is presented as a smart parking system with a review of its benefits and issues. Smart parking system can be a great option nowadays due to the prevalence of the smartphones and the people's reliance on its applications in their daily lives.
Enhancing the cities services and helping to improve the sustainable development of cities are two of the major drivers of smart city concept. Some of future suggestions to improve smart parking application work in Jeddah include enhancements in technologies, components and features. These might include utilizing advanced technologies to enhance the structure of the application and its services, such technologies that have a major position in this context are Internet of things IoT, cloud computing, using of crowdsourcing [15] and big data. Moreover, smart parking mobile application should provide addition functions such as reserve a space with charging energy for electric vehicles (EVs) [16]. Finally, on the long-term, smart parking should provide more space for gardening or expand living spaces. That convey the urban interfaces to more natural landscapes [17]. 


\section{REFERENCES}

[1] Sanseverino, E. R Sanseverino, R. R. Vaccaro, V. and Zizzo, G. Smart Rules for Smart Cities, Cham Heidelberg New York Dordrecht London: Springer, 2014.

[2] Obaidat M. S. and Nicopolitidis, P. Smart Cities and Homes: Key Enabling Technologies, Morgan Kaufmann, 2016.

[3] Jeddah Municipality, Jeddah Municipality Achievements, [Online]. [Accessed 31-3-2017].

[4] Thaker, J. Your parking can talk - smart parking is the solution, Softweb Solution, 25-5-2015. [Online]. Available: http://www.softwebsolutions.com/resources/smartparking-iot-solution.html. [Accessed 29-3-2017].

[5] Jeddah Public Transportation Study, Saudi Arabia: Ministry of Transportation, 13, Jeddah: Transport Policy, 2007, pp. 445-446.

[6] Bélissent, J. Getting Clever About Smart Cities: New Opportunities Require New Business Models, Forrester, Cambridge, 2010.

[7] What is Smart Parking? Repsol, [Online]. Available: https://www.repsol.com/es_en/energiainteligente/informate/smart-parking.aspx. [Accessed 293- 2017].

[8] Miller, M. The Internet of Things: How Smart TVs, Smart Cars, Smart Homes, and Smart Cities Are Changing the World, Pearson Education, 2015.

[9] Aljoufie, M. Analysis of Illegal Parking Behavior in Jeddah, Scientific Research Publishing,Current Urban Studies, 4, 2016, pp. 393.

[10] Aljoufie, M. Zuidgeest, M. Brussel, M. and Maarseveen,V. Spatial-Temporal Analysis of Urban
Growth and Transportation in Jeddah City, Saudi Arabia, Cities, Elsevier, 31, 2013, pp. 57 - 68.

[11] Kumar, S. Smart city solutions - Smart Parking Lots, Electronics of Things, 16 Mar. 2016. [Online]. Available: http://electronicsofthings.com/expert-opinion/smart-citysolutions-smart-parking-lots/. [Accessed 1-4-2017].

[12] STC, Coverage Maps, [online] Available: http://www.stc.com.sa/wps/wcm/connect/english/helpAn $\mathrm{dSupport/storelocator}$

[13] J Yang, J. Portilla, J. and Riesgo, T. Smart parking service based on wireless sensor networks, IECON 2012 38th Annual Conference on IEEE Industrial Electronics Society, 2012, pp. 6029- 6034.

[14] Pham, T. N., Tsai, M. F., Nguyen, D. B., Dow, C. R., and Deng, D. J. A cloud-based smart-parking system based on Internet-of-Things technologies. IEEE Access, 3, 2015, pp. 1581-1591

[15] Chen, X. Santos-Neto, E. and Ripeanu, M Crowdsourcing for On-street Smart Parking, Proceedings of the second ACM international symposium on design and analysis of intelligent vehicular networks and applications, Cyprus, 2012, pp. 1- 8 .

[16] He, T. Bai, Y. and Zhu, J. Optimal Charging Strategy of Electric Vehicles Customers in a Smart Electrical Car Park, 8th IET International Conference on Power Electronics, Machines and Drives (PEMD 2016), Sydney, 2016, pp. 1 - 6.

[17] Rucks, G. and Guevara-Stone, L. How smart parking solutions can transform cities, GreenBiz, 2013. [Online]. Available: https://www.greenbiz.com/blog/2013/10/30/how-smartparking-solutions-can-transform-cities-0. [Accessed 303-2017 